\title{
ORIGENS DO ENSINO DE BIBLIOTECONOMIA NO BRASIL
}

\author{
Marcos Leandro Freitas Hubner \\ Doutorando no Programa de Pós-Graduação em Ciência \\ da Informação na Universidade de São Paulo, Brasil. \\ marcos.hubner@unir.br \\ http://orcid.org/0000-0002-4467-2752
}

\author{
Jose Fernando Modesto Silva \\ Doutor em Ciências da Comunicação pela Universidade \\ de São Paulo. Professor da Universidade \\ de São Paulo, Brasil. \\ fmodesto@usp.br \\ https://orcid.org/0000-0002-0535-5471
} Alessandra Atti
Mestranda no Programa de Pós-Graduação em Ciência
da Informação pela Universidade de São Paulo, Brasil.
alessandraatti@hotmail.com
https://orcid.org/0000-0001-7198-5087

\section{RESUMO}

O artigo tem por objetivo apresentar acontecimentos que marcaram o início do ensino de Biblioteconomia na França e nos Estados Unidos, com experiências relevantes que inspiraram as escolas no Brasil. Retrata a trajetória histórica da École des Chartes, criada na França, em 1821, com a missão de formar futuros curadores patrimoniais, especialmente para bibliotecas, sem, entretanto, constituir-se em curso de Biblioteconomia. $O$ artigo foi elaborado a partir de revisão bibliográfica em publicações científicas que abordam a história do ensino de Biblioteconomia. A gênese da Biblioteconomia moderna, entretanto, remete ao início do século XIX, na Alemanha, em que, em 1886, surgiu o primeiro curso superior de Biblioteconomia, na Universidade de Göttingen. As práticas biblioteconômicas norte-americanas foram significativamente influenciadas pela experiência alemã. Em 1887, por iniciativa de Melvin Dewey, ocorreu a criação da primeira escola de Biblioteconomia, nos Estados Unidos, na Columbia College, e contava com uma forte tendência técnico-vocacional. Após essa iniciativa pioneira, novas escolas foram criadas nos Estados Unidos, entretanto sem um padrão de qualidade definido. Isso obrigou a elaboração de um documento da ALA, com recomendações mínimas, para os cursos de Biblioteconomia. Em 1928, ocorreu a criação da Graduate Library School, em Chicago, estabelecendo um novo padrão para a formação dos bibliotecários naquele país. No Brasil, o ensino de Biblioteconomia desenvolveu-se a partir da fusão de diferentes influências oriundas desses países, culminando no cenário atual do país em relação à formação de bibliotecários e bibliotecárias.

Palavras-chave: Ensino de Biblioteconomia. École des Chartes. Library Schools. Formação do bibliotecário. Escolas de Biblioteconomia.

\section{THE ORIGINS OF LIBRARIANSHIP TEACHING IN BRAZIL}

\section{ABSTRACT}

The article aims to present events that marked the beginning of theLibrarianship teaching in France and the United States, with relevant experiences which inspired the schools in Brazil. It approaches the history of the École des Chartes, created inf France in 1821, with the mission of create new patrimonial curators, especially for Libraries, without, however to result in a Librarianship course. The article was elaborated from a bibliographic review in scientific publications that approach the history of the teaching of Librarianship. The origin of modern librarianship, however, goes back to the beginning of the XIX century in Germany, where, in 1886, there was the first academical course of Librarianship in the University of Göttingen. The North American librarianship practices were deeply influenced by the German experience. In 1887, as a Melvin Dewey initiative, there was the creation of the first Librarianship school in the United States, at Columbia University, with a strong technovocacional tendency. after the pioneering iniative, new schools were created at the United States, but not with a definite quality. That forced the constitutition of an ALA documente with the minimal recommendations required for the courses of the librarianshio. In 1928 there was the creation of the Graduate Library School in Chigago establishing a new pattern for the graduation of the librarians in that country. In Brazil, the Librarianship teaching developed from the fusion of different influences from the countries cited above, resulting on our current national scenery in relation to the graduation of new librarians. 
Keywords: Education for librarianship. École des Chartes. Library Schools. Librarian training. Schools of librarianship.

\section{INTRODUÇÃO}

A necessidade de profissionais qualificados e detentores de um conhecimento mais amplo sobre as bibliotecas e seus serviços, em franca expansão no século XIX, congregou esforços para a formação técnica e teórica de bibliotecários e levou ao surgimento das primeiras escolas de Biblioteconomia.

No Brasil, também advém a necessidade da implementação de práticas biblioteconômicas, visando à melhor gestão e organização das bibliotecas. Surgem, então, no início do século $\mathrm{XX}$, as duas escolas pioneiras na formação de bibliotecários no país, cada qual com características muito distintas: o curso da Biblioteca Nacional, com um perfil mais humanista, influenciado pela escola francesa - a École Nationale des Chartes; e o curso da escola paulista de Biblioteconomia, com um perfil mais tecnicista, influenciado pela escola norte-americana (DIAS, 1955; RUSSO, 1966; CASTRO, 2000; SOUZA, 2009; MUELLER, 1985; FONSECA, 2007; WEITZEL, 2010; ALMEIDA, 2012).

Torna-se imperioso, portanto, a partir de uma criteriosa revisão bibliográfica, uma abordagem mais aprofundada sobre as duas escolas, a francesa e a norte-americana, retratadas, na maioria das vezes, de forma genérica. Ambas exerceram uma significativa influência na formação dos bibliotecários brasileiros, tanto diretamente, com a inserção de egressos no mercado de trabalho, quanto indiretamente, através dos diversos cursos originados a partir delas em nosso país. A disponibilização, nos dias atuais, de diversos documentos históricos, em meios virtuais, possibilita o aprofundamento de informações sobre as escolas pioneiras no ensino de Biblioteconomia, no Brasil, e, por esse motivo, o presente artigo apresenta uma revisão bibliográfica sobre a escola francesa, a École Nationale des Chartes de Paris, e a escola norte-americana, a Library Schools. a School of Library Economy, fundado por Melvil Dewey, na Columbia University, em Nova York. 


\section{ESCOLA FRANCESA: ÉCOLE NATIONALE DES CHARTES}

Fonte: Texier (2014)

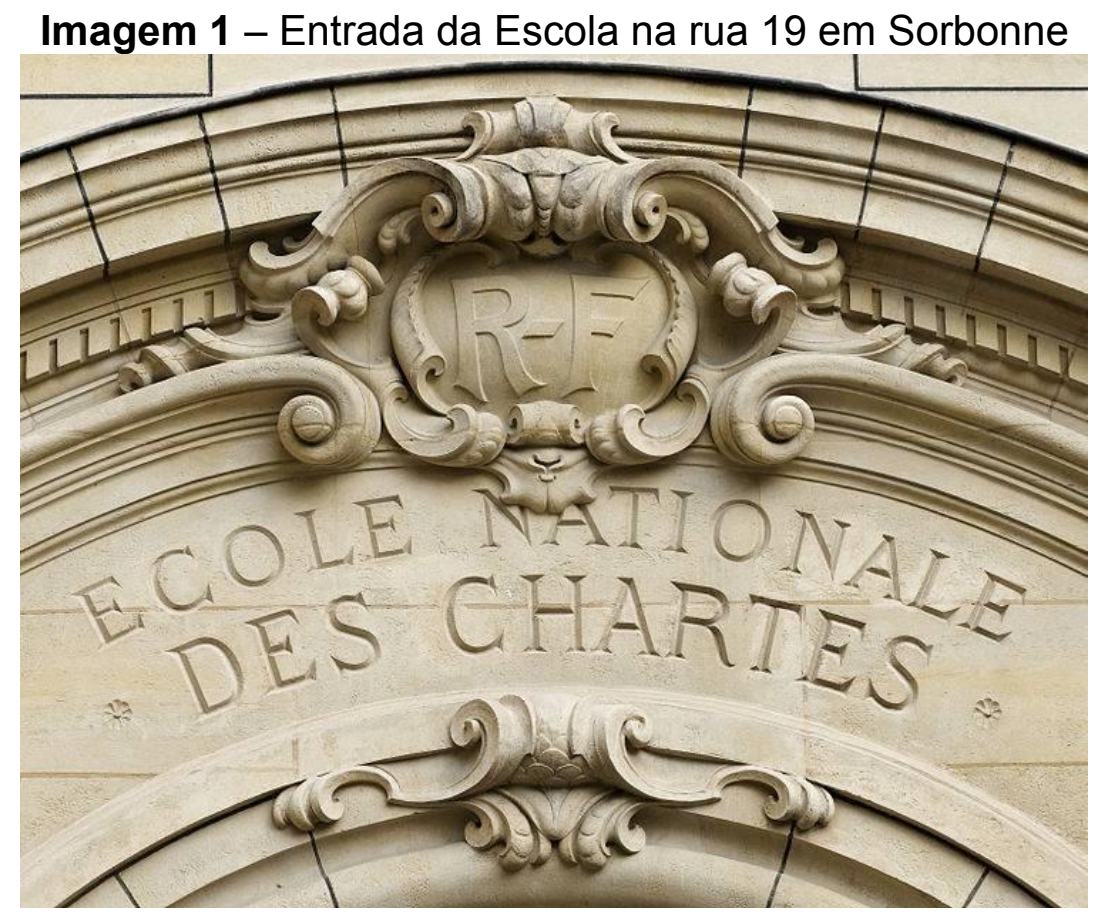

No início do Século XIX, a França passava por momentos de grande transformação, envolvendo vários aspectos, dentre os quais se destacam:

- Políticos: Tomando-se a Revolução Francesa, em 1789, como ponto de partida, decorrem diversos eventos que transformam a política do país nos anos vindouros: queda da monarquia, em 1792; guerras napoleônicas, que levam à expansão do império francês, entre os anos 1800 e 1812; a queda de Napoleão, em 1814, e a volta da Família Bourbon ao poder, com a coroação do rei Luís XVIII (MORAES, 2017). Além disso, é importante ressaltar-se a inserção da política nos espaços rotineiros da população. Para Moraes (2017, p.71), "a política foi deixando o espaço reservado de gabinetes governamentais e passou a fazer parte do espaço público: decisões de governo passaram a ser não só tomadas, elas agora eram justificadas, explicadas, transmitidas a um público que as ouvia e reagia";

- Sociais/Econômicos: Com a população exaurida, após duas décadas de guerras, o país vivia uma crise social interna, aprofundada pelo aumento do custo de vida. A monarquia enfrentava sérios problemas financeiros, impossibilitando investimentos na reconstrução do país. Somava-se a isso, um grande atraso tecnológico (FORTESCUE, 1992); 
- Culturais: Pensadores iluministas como Voltaire ${ }^{1}$, Rousseau$^{2}$ e Montesquieu ${ }^{3}$ defendiam, entre outros ideais, a valorização da Ciência e criticavam o Antigo Regime, sistema político baseado no poder absoluto do rei (Absolutismo) (COSTA, 1999). Além disso, houve um processo de politização da cultura popular, conforme Chartier (2009).

Particularmente no que se relaciona à Biblioteconomia, houve um movimento de disseminação do conhecimento, resultando no aumento da escolarização da população e socialização do livro (PALLIER, 1994). Além disso, segundo Mey e Silveira (2009), uma das ações da Revolução Francesa, coordenada por seus dirigentes revolucionários, foi o confisco de grandes bibliotecas particulares, as quais foram transformadas em bibliotecas públicas, propiciando um acesso mais amplo da população a esses espaços. Pallier (1994), corroborando essa informação, destaca que, antes da Revolução, havia dez bibliotecas municipais, porém, após o ano de 1803, somavam-se, provavelmente, mais de duzentas.

Sobrevém, em decorrência dessas transformações, a necessidade de profissionais devidamente preparados para trabalhar nas novas bibliotecas e, em 22 de fevereiro de 1821, a École des Chartes foi fundada através de uma Ordem Real ${ }^{4}$. Quanto ao ato de criação, Martin (1972) relata que o Rei Luís XVIII o efetivou, porém se acredita que Napoleão Bonaparte, por ser patrono da l'Académie des inscriptions et belles lettres ${ }^{5}$, já tenha vislumbrado a criação da escola. A missão da escola, na sua gênese, era formar futuros curadores patrimoniais, especialmente em bibliotecas, conforme enfatizado por Charon, Diu e Parinet (2005).

A versão de que o projeto de criação da École des Chartes tenha sido idealizado anteriormente à sua real fundação encontra respaldo em Delpit (1840), quando da publicação do primeiro fascículo da obra Bibliothèque de l'École des Chartes $^{6}$, o periódico oficial da Escola. Conforme Delpit, a ideia inicial da criação da Escola coube ao Barão de Gerando, Secretário-Geral do Ministério do Interior em 1806, o qual propôs a fundação de uma grande instituição nacional, na qual os estudiosos mais experientes iriam trabalhar

\footnotetext{
${ }^{1}$ François-Marie Arouet (Paris, 21 de novembro de 1694 - Paris, 30 de maio de 1778).

2 Jean-Jacques Rousseau (Genebra, 28 de Junho de 1712 - Ermenonville, 2 de Julho de 1778).

${ }^{3}$ Charles-Louis de Secondat (Bordéus, 18 de Janeiro de 1689 - Paris, 10 de Fevereiro de 1755).

${ }^{4} \mathrm{https}: / /$ www.persee.fr/doc/bec_0373-6237_1840_num_1_1_444237\#bec_0373-

6237_1840_num_1_1_T1_0026_0000

5 l'Académie des inscriptions et belles lettres - Fundada em 1663, sob o reinado de Luís XIV, e por iniciativa de Colbert, é uma das cinco Academias do I'Institut de France. O papel científico da l'Académie des inscriptions et belles lettres se manifesta diretamente nas atividades de encorajamento que dão a muitas organizações de ensino e pesquisa. http://www.aibl.fr/presentation/?lang=fr

${ }^{6} \mathrm{https}: / / \mathrm{www}$. persee.fr/collection/bec
} 
na formação dos curadores do conhecimento e dos manuscritos da Idade Média. Esses jovens iriam se destacar por sua educação e pelo apreço para com as ciências históricas. O projeto foi levado ao Ministro do Interior, o Duque de Cadore, o qual prontamente o submeteu ao Imperador. Napoleão Bonaparte aprovou a ideia, porém solicitou informações com um maior detalhamento. Infelizmente, tão logo o aceite do Imperador, a França entrou em uma nova Guerra e o projeto findou abandonado.

Uma vez em atividade, as aulas aconteciam na Biblioteca Real e no Arquivo Imperial, não havendo um local fixo. Havia somente dois professores, os quais foram recrutados um de cada instituição hospedeira do curso. Eram eles Abbé de Lespine e M. Povillet: o primeiro, ex-cônego da catedral de Périgueux, com a experiência de ter trabalhado, durante vinte anos, nos manuscritos da Biblioteca Real; o segundo foi chefe da seção histórica dos arquivos imperiais e ex-chefe de gabinete da ordem do Espírito Santo (DELPIT, 1840). A Escola estava sob a autoridade conjunta do Conservateur des manuscrits de la Bibliothèque Royale ${ }^{7}$ e do Garde des Archives de la Archives impériales ${ }^{8}$, sendo o Ministro do Interior o responsável geral pela Escola, conforme os artigos $5^{\circ}$ e $6^{\circ}$ da Ordem Real que estabeleceu a École des Chartes. As primeiras disciplinas oferecidas foram bibliografia e classificação de bibliotecas, serviço de biblioteca. O número de alunos foi fixado em 12, os quais seriam nomeados pelo Ministro do Interior, propostos pela l'Académie des inscriptions et belles lettres, e receberiam um salário durante os dois anos do curso. Há informações, contudo, de que o salário não foi pago, ocasionando, a partir de 19 de dezembro de 1823, a interrupção do curso por falta de ouvintes (MARTIN, 1997).

O fechamento do curso causou grande repercussão junto à sociedade erudita da época, bem como na l'Académie des inscriptions et belles lettres, fato que compeliu o Ministro do Interior - Conde de la Bourdonnaye - a encarregar o chefe de gabinete de seu ministério de redigir um relatório que serviu de base para uma nova ordenação real ${ }^{9}$ em 19 de dezembro de 1829 (MARTIN, 1977). A partir de então, adotando o nome de L'École Royale des Chartes, o curso passou a ter a duração de três anos, com um novo processo de seleção, requerendo, apenas, a idade mínima de dezoito anos e a comprovação de ser bacharel, conforme 0 art. $3^{\circ}$ do Decreto Real. Houve, também, visando à permanência dos alunos, a definição de uma espécie de bolsa e, ao final

\footnotetext{
7 Curadoria dos manuscritos da Biblioteca Real.

8 Guardião Geral dos Arquivos Imperiais.

9 https://www.persee.fr/doc/bec_0373-6237_1840_num_1_1_444237\#bec_0373-

6237_1840_num_1_1_T1_0032_0000
} 
do primeiro ano, foi aberta uma disputa com o objetivo de selecionar de seis a oito alunos, os quais passariam a receber um salário de 800 francos, além de desempenharem seus trabalhos na Biblioteca Real e no Arquivo Imperial. Na França, sempre houve uma preocupação com a formação do bibliotecário, o qual deveria ser dotado de uma ampla e sólida formação cultural e científica, além de possuir habilidades específicas para o bom desempenho do cargo (PALLIER, 1994).

No ano de 1846, ocorreu uma reorganização do ensino, facultando uma nova e real existência para a École des Chartes, conforme Decreto ${ }^{10}$ de 31 de dezembro daquele ano, com inserção de novas disciplinas, algumas das quais ainda ministradas nos dias atuais (BETTANT, 2012). Essa reestruturação curricular, que passou a vigorar a partir do dia $1^{\circ}$ de janeiro de 1847 , proporcionava um enfoque maior para a organização das bibliotecas. No Quadro 1, é possível visualizar as disciplinas e o conteúdo a ser desenvolvido conforme 0 artigo $8^{\circ}$ do Decreto de 31 de dezembro de 1846. Entre as disciplinas, destacavam-se paleografia, sigilografia, numismática, filologia, classificação de arquivos e bibliotecas, geografia histórica, sistema de moedas e pesos e medidas, história das instituições políticas da França, arqueologia, direito civil, direito canônico e direito feudal. Ao concluir a sua formação de três anos, os egressos passaram a ser chamados de Arquivistas Paleógrafos, conforme o artigo 19 do Decreto.

Quadro 1 - Disciplinas ofertadas pela École des Chartes a partir de 1847

\begin{tabular}{|c|c|}
\hline Disciplinas & Conteúdo \\
\hline Paleografia & Leitura e decifração de cartas e monumentos escritos; \\
\hline Arqueologia & $\begin{array}{l}\text { Arqueologia figurativa, abrangendo a história da arte, arquitetura cristã, } \\
\text { sigilografia e numismática; }\end{array}$ \\
\hline Diplomática & $\begin{array}{l}\text { A história geral da Idade Média, aplicada particularmente à cronologia, } \\
\text { à arte de verificar a idade dos títulos e sua autenticidade; }\end{array}$ \\
\hline $\begin{array}{l}\text { Filologia } \\
\text { Geografia Histórica }\end{array}$ & $\begin{array}{l}\text { Linguística aplicada à história das origens e formação da língua nacional; } \\
\text { A geografia política da Franca na Idade Média: }\end{array}$ \\
\hline História do Direito & $\begin{array}{l}\text { Resumo do conhecimento dos princípios do direito canônico e do } \\
\text { direito feudal. }\end{array}$ \\
\hline
\end{tabular}

Fonte: Adaptação realizada pelo autor a partir do artigo $8^{\circ}$ do Decreto de 31 de dezembro de 1846.

A partir do novo decreto, a Escola ficou sob a responsabilidade de um diretor nomeado pelo Ministro de Instrução Pública e sob a supervisão do Conselho de Educação. Com o novo currículo, mais estruturado, e contando com novas instalações, a Escola adquiriu prestígio, não somente na França, mas também em todo o continente europeu,

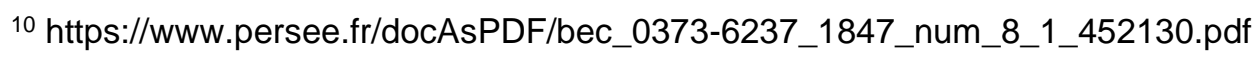


passando a receber visitas de pesquisadores como, por exemplo, do professor Frédéricq ${ }^{11}$ (1883), que, após algumas idas à École des Chartes, destacou que os ensinamentos ministrados na escola possuíam um propósito científico e profissional, tratando-se de uma escola de vanguarda. Em 1848, ocorreu uma nova mudança no nome oficial da Escola, até então denominada Royal School of Chartes, passando a ser École Nationale des Chartes, conforme a publicação Bibliothèque de l'École des Chartes de 1848.

Considerando o contexto histórico e uma forte tradição local, muitas posições destinadas a bibliotecários foram reservadas, de forma escusa, para pessoas literárias ou simplesmente amigos do poder. Esse posicionamento fez com que, em 1867, dos 222 ex-alunos da escola, apenas quinze tivessem conseguido empregos como bibliotecários, dos quais treze em Paris e dois nas províncias, gerando uma grande insatisfação por parte do corpo docente da escola. Tal situação só foi contornada a partir do último quarto do século (MARTIN, 1977).

Dificuldades relacionadas aos espaços físicos acompanharam a trajetória da escola até recentemente, quando ela, finalmente, passou a ocupar um espaço exclusivo. Ao longo de sua história, as instalações provisórias foram uma constante. Quando de sua criação, as aulas dividiam-se entre a Biblioteca Real e o Arquivo Imperial. Em 1830, após a sua reabertura, a escola passou a ocupar somente os espaços da Biblioteca Real, contando, a partir de então, com espaço para as atividades administrativas. Esse espaço, porém, localizava-se no sótão do prédio, com problemas de oscilação de temperatura, descritos por Demante (1898) da seguinte forma: um sótão no qual o calor era sufocante durante o verão, e os tremores de frio era uma rotina no inverno.

Em 1846, a Escola foi transferida para um novo espaço: o Hotel Clisson, com instalações mais amplas, permitindo a criação de uma biblioteca própria. A nova realidade propiciou uma expansão das atividades da escola, com a caracterização dos espaços, aquisição de equipamentos técnicos, além do desenvolvimento de atividades de pesquisa científica e a multiplicação de atores, pois o número de professores foi ampliado para sete (HOTTIN, 1999). O novo espaço pode ser visualizado na Imagem 2, a qual mostra a fachada de entrada do Hotel Clisson.

11 Históriador Belga, Professor da Universidade Gent - https://www.ugentmemorie.be/personen/fredericqpaul-1850-1920. 


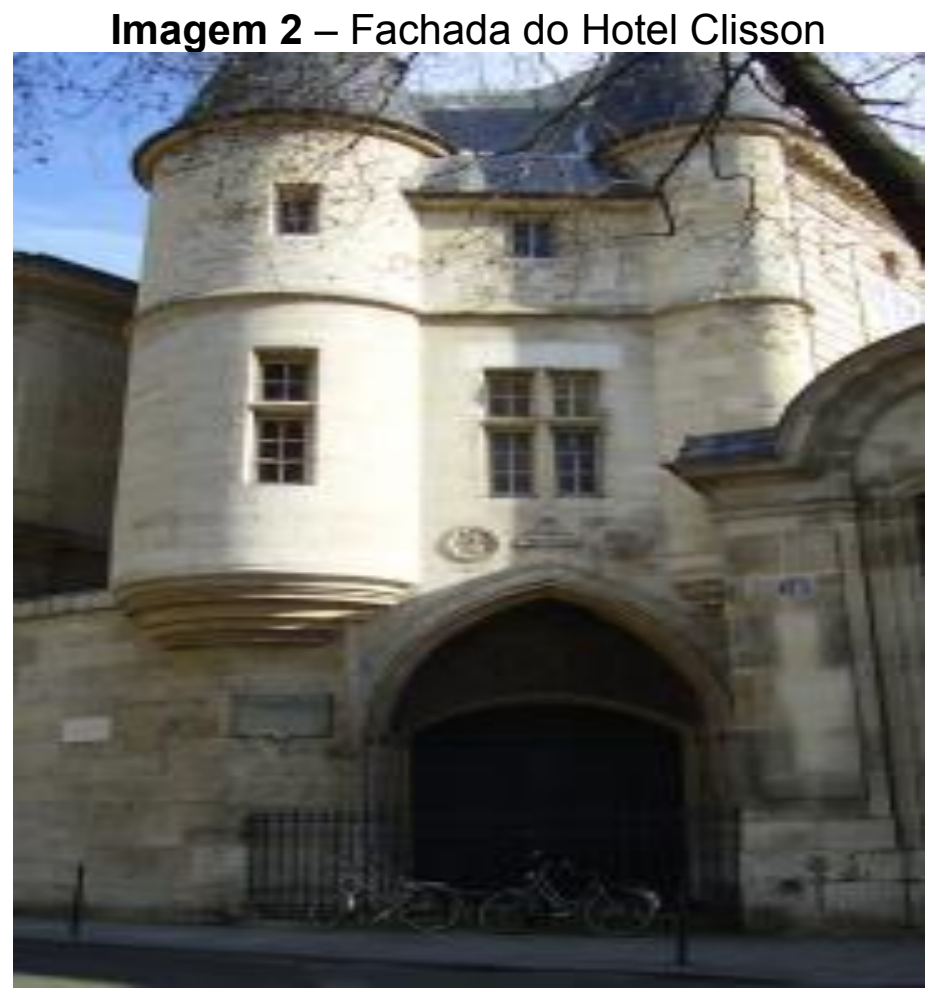

Fonte: ÉCOLE (2016)

No entanto, em 1866, em face do aumento das coleções da biblioteca e do número de alunos, a instituição ganhou um novo endereço, localizado na 18 Rue de Paradis. A mudança gerou insatisfação dos membros da Escola, pois o espaço era insuficiente para as necessidades da escola, com a biblioteca ocupando cerca de $40 \%$ do espaço físico destinado a ela, além de estar localizada junto a uma unidade do Arquivo Imperial, ficando afastada das demais instituições de ensino superior (HOTTIN, 1999).

Uma nova mudança, em 1897, levou a escola à rua de la Sorbonne 19, nas instalações originalmente ocupadas pela Faculdade de Teologia Católica de Paris. A mudança propiciou um contato mais próximo com outras instituições de pesquisa e ensino sediadas na Sorbonne, algo reivindicado, reiteradamente, pela comunidade acadêmica, quando da mudança para 18 rue de Paradis (HOTTIN, 1999).

Em 2005, a Escola atualizou os propósitos de sua missão, através da publicação do Decreto $\mathrm{n}^{\circ}$ 2005-1751 de 30 de dezembro de 2005 ${ }^{12}$, ficando, dessa forma, definido: "École Nationale des Chartes tem como missão a formação de pessoal científico de arquivos e bibliotecas". Assim, ratificou seu compromisso com a formação de profissionais que irão contribuir para o desenvolvimento do patrimônio nacional e do conhecimento científico.

12 https://www.legifrance.gouv.fr/affichTexte.do?cidTexte=JORFTEXT000000268383, 
Em outubro de 2014, a Escola passou a ocupar um espaço próprio, algo almejado desde a sua criação, passando a localizar-se na rua Richelieu, 65, no seu bairro original, ficando próxima à Biblioteca Nacional da França, ao Instituto Nacional do Patrimônio, ao Instituto Nacional de História da Arte, à École du Louvre e ao Ministério da Cultura. As novas instalações garantiram espaços amplos para as salas de aulas e de estudos, para a tradicional biblioteca, laboratórios para as atividades práticas, auditório, além de se adequar às novas tecnologias, tão presentes no cotidiano universitário.

Assim, a trajetória histórica da École des Chartes evidencia que a Instituição sempre primou por manter a sua a vocação de proporcionar uma formação baseada na análise, na crítica e no aprimoramento de textos e de documentos (MARTIN, 1977). Ao encontro disso, Charon, Diu e Parinet (2005) enfatizam que a formação sempre esteve orientada principalmente para a investigação, sem visar especificamente aos objetivos profissionais. Em consonância, destacam que o objetivo da Escola sempre foi o de possibilitar que os futuros responsáveis pelas coleções estivessem familiarizados com os acervos pelos quais seriam responsáveis, oferecendo, dessa forma, uma abordagem histórica e crítica dos documentos reunidos nas coleções.

\section{ESCOLA NORTE-AMERICANA: LIBRARY SCHOOLS}

A influência da escola norte-americana de Biblioteconomia é notória, com destaque para a escola de Biblioteconomia da Escola Livre de Sociologia e Política de São Paulo, responsável pela implantação de um modelo mais voltado às técnicas, baseado nas Library Schools norte-americanas (PRADO, 1988). Buscando conhecer um pouco mais sobre esse modelo implantado na formação de bibliotecários no Brasil, fez-se necessário conhecer com mais detalhes a sua origem.

A primeira escola de Biblioteconomia norte-americana foi implantada por Melvin Dewey, a School of Library Economy, na Columbia University em Nova York, fruto de um percurso que, no seu primórdio, foi fortemente influenciado pela Alemanha do início do século XIX, país considerado gênese da Biblioteconomia moderna (RICHARDSON JR., 2010). Atualmente, denominada Library Science pelos norte-americanos, e Bibliothekswissenschaft pelos alemães, sua criação é atribuída a Martin Willibald 
Schrettinger ${ }^{13}$ (HJØRLAND, 2018), bibliotecário responsável pela finalização do catálogo alfabético da Biblioteca Estadual da Baviera, em 1818.

$\mathrm{O}$ uso do termo Bibliothekswissenschaft ${ }^{14}$ é atribuído a Schrettinger quando mencionou a seguinte frase: "dissipar a quimera da técnica detalhada é lançar as bases da Biblioteconomia15" (HESSEL, 1955, p.80, tradução pessoal) junto a sua clássica obra: "Versuch eines vollständigen Lehrbuches der Bibliothek-Wissenschaft oder Anleitung zur vollkommenen Geschäftsführung eines Bibliothekärs ${ }^{16 "}$, publicada entre os anos de 1808 (v.1) e 1829 (v.2). O trabalho iniciado por ele encontrou continuidade com Friedrich Adolf Ebert ${ }^{17}$, bibliógrafo e bibliotecário alemão responsável pela obra Die Bildung des Bibliothekars ${ }^{18}$, que teve forte influência no trabalho desenvolvido pelos bibliotecários norte-americanos no século XIX (WINGER, 1961).

A concepção que Ebert tinha sobre a Biblioteconomia era inovadora para sua época, resultante da evolução de vários métodos de estudo finalmente reunidos, propiciando uma grande massa de trabalho literário. As bibliotecas eram vistas como "arquivos científicos para as gerações futuras", ao contrário de instituições projetadas para afetar direta e imediatamente o cotidiano das pessoas como, por exemplo, escolas e universidades. Dessa maneira, o profissional bibliotecário, conforme projetado por Ebert, deveria estar preparado para estudar e apreciar os textos literários atemporais e os trabalhos acadêmicos em suas línguas originais, com profundo conhecimento de história, línguas, história literária, bibliografia e diplomática básica, características da formação europeia. Porém, o fator que o distinguiu e que conquistou admiração dos bibliotecários norte-americanos foi a ênfase colocada no sistema geral e na importância da gestão para efetivo sucesso da biblioteca. Um exemplo disso seria a realização de exame para nomeação para os cargos técnicos e administrativos, que deveriam estar em harmonia com as práticas desenvolvidas (WINGER, 1961). É importante ressaltar que a Biblioteconomia alemã, durante o século XIX, possuía enorme conhecimento sobre as bibliotecas universitárias.

Ainda durante aquele período, fortificou-se o movimento visando tornar a Biblioteconomia uma profissão, culminando com o estabelecimento de treinamentos

\footnotetext{
${ }^{13}$ Martin Willibald Schrettinger (1772-1851) foi um padre e bibliotecário alemão. Informação obtida junto The Emerald Handbook of Modern Information Management.

14 Biblioteconomia.

15 To dispel the chimera of detailed technique is to lay the foundation of library Science.

${ }^{16}$ Experimente um livro completo de Biblioteconomia ou um guia bibliotecário perfeito.

17 Friedrich Adolf Ebert (1799-1834).

18 The Education of the Librarian, (Leipzig: Steinacker \& Wagner, 1820).
} 
para formar bibliotecários. O primeiro curso oficial de Biblioteconomia ocorreu na Universidade de Göttingen, em 1886, ministrado pelo reconhecido professor e bibliotecário Karl Franz Otto Dziatzko ${ }^{19}$ (HESSEL, 1955).

No referencial teórico nacional, são escassos os registros sobre a importância da Biblioteconomia desenvolvida na Alemanha. Algo similar aconteceu nos Estados Unidos, em relação à influência germânica na Biblioteconomia norte-americana durante o século XIX, como destaca Richardson Jr. (2010). O autor, porém, mostra-se reticente em relação a isso, chegando a citar o fato de que milhares de norte-americanos estudaram na Alemanha antes da Primeira Guerra Mundial.

A Biblioteconomia norte-americana, na segunda metade do Século XIX, desenvolveu-se de maneira consciente e autossuficiente, com profissionais capacitados, entre os quais destacaram-se Charles Coffin Jewett ${ }^{20}$, John Shaw Billings ${ }^{21}$, William Frederick Poole ${ }^{22}$, Melvil Dewey ${ }^{23}$, Charles Ammi Cutter ${ }^{24}$ (RICHARDSON JR., 2010a).

Nesse contexto, um movimento visando à identificação e à consolidação da profissão de Bibliotecário, similar ao que ocorria na Grã-Bretanha, Alemanha e outros países da Europa, passou a ocorrer nos Estados Unidos. Em 1853, aconteceu a primeira tentativa de organização a partir de uma convenção de bibliotecários (WINGER, 1961). Somente treze anos depois, em 1876, foi fundada a American Library Association (ALA), na Filadélfia. Entre os presentes e fundadores estavam William Frederick Poole, Charles Ammi Cutter e Melvil Dewey.

Em 1879, Melvil Dewey propôs um programa sistemático de aprendizagem em reunião da ALA, que não conquistou a simpatia dos colegas bibliotecários. Em 1883, com a mudança para o Columbia College, onde passou a responder pela biblioteca, Dewey preconizou a criação de uma escola de Biblioteconomia, argumentando que tal escola era requerida não somente por pessoas leigas no assunto, mas também por um expressivo

\footnotetext{
${ }^{19}$ Karl Franz Otto Dziatzko (1842-1903) Bibliotecário, pesquisador e primeiro professor de Biblioteconomia. Responsável pelas bases das Instruções Prussianas publicadas em 1899 (QUINN, 2014).

${ }^{20}$ Charles Coffin Jewett (1816-1868) Bibliotecário e professor de línguas modernas. Defensor dos catálogos alfabéticos (QUINN, 2014).

21 John Shaw Billings (1838-1913) Cirurgião e bibliotecário americano. Criador do Index Medicus (QUINN, 2014).

22 William Frederick Poole (1821-1894) Bibliógrafo e gestor de bibliotecas. Criador do Índice de Poole para Literatura Periódica (QUINN, 2014).

${ }^{23}$ Melvil Dewey (1851-1931) Bibliotecário. Criou a Classificação Decimal de Dewey, foi um dos maiores responsáveis pelo desenvolvimento da biblioteconomia nos Estados Unidos (QUINN, 2014).

24 Charles Ammi Cutter (1837-1903) Bibliotecário e estudioso dos catálogos. Responsável pela criação do esquema de Classificação Expansiva, ainda em uso parcial no sistema de catalogação da Biblioteca do Congresso (QUINN, 2014).
} 
contingente dos cerca de cinco mil bibliotecários norte-americanos daquele momento. A escola seria uma oportunidade de esses profissionais aproximarem-se dos métodos da Biblioteconomia moderna (WINGER, 1961).

$\mathrm{Na}$ Conferência da ALA, em Buffalo, em 1883, Dewey apresentou, de maneira superficial, o curso, informando que não seria extenso e desenvolveria apenas as exigências técnicas do trabalho do bibliotecário. Dewey destacou que o objetivo do curso era ser totalmente prático, buscando atender a situações do cotidiano de uma biblioteca, além de incluir noções de administração (RAYWARD, 1968). Ainda segundo este autor, a desconfiança e a cautela, por parte de integrantes da ALA, ficaram evidentes, já que esperavam um modelo semelhante ao europeu, ou seja, de um bibliotecário mais erudito.

Além da desconfiança, Dewey sofreu resistência do Conselho de Curadores do Columbia College, pois o curso seria ofertado também para mulheres, objeção que permaneceu, inclusive, após o início do curso (ROCKWOOD, 1968; RAYWARD, 1968). Em 1884, o Conselho de Curadores do Columbia College aprovou resolução estabelecendo uma Escola de Economia de Bibliotecas e a nova Associação de Bibliotecas Americanas (ALA) aprovou o curso, que, porém, ficou sob observação, sem emissão da chancela que Dewey gostaria de receber por parte da ALA (ROCKWOOD, 1968).

Conforme Rockwood (1968), a primeira aula do novo curso aconteceu no dia 5 de janeiro de 1887, um ano após a criação do curso alemão na Universidade de Göttingen, ministrado por Karl Dziatzko. A respeito de qual foi o primeiro curso de Biblioteconomia, Grogan (2007) destaca que, mesmo após se passar mais de um século, algumas questões ainda permanecem sem resolução.

A Escola de Economia de Bibliotecas possuía uma forte tendência técnico-vocacional, dando destaque central aos detalhes específicos da prática da biblioteca. O plano inicial era de três meses de aula, porém foram necessários ajustes no transcorrer do período. Foi definido o prazo de quatro meses, combinado com a possibilidade de os alunos utilizarem até dois anos adicionais na realização de atividades práticas na biblioteca da Columbia College, da qual Dewey era o diretor (MIKSA, 1988). A primeira turma era composta por 20 alunos. No turno da manhã, aconteciam as aulas teóricas de classificação, catalogação, referência, administração de bibliotecas e bibliografia e, no turno da tarde, havia palestras, visitas às bibliotecas e desenvolvimento de atividades práticas na biblioteca (ROCKWOOD, 1968). 
Em 1888, o cursou foi segmentado em três partes, dentro de um espaço de sete meses, além dos dois anos adicionais para a realização de atividades práticas. As pressões recebidas por Dewey de parte do Conselho de Curadores do Columbia College continuavam grandes, devido à presença de mulheres no curso, além da desconfiança da ALA sobre o método de ensino empregado. Em 1889, ocorreu a transferência da escola para a Biblioteca do Estado de Nova York, em Albany, tendo Dewey aceitado o cargo de direção, além de contar com curadores sem objeção ao ingresso de mulheres. Em Albany, Dewey estabeleceu um plano curricular de educação bibliotecária que serviu como padrão por várias décadas: um programa de dois anos, que se desenvolvia a partir de uma ênfase no trabalho prático (aprendiz) até a construção de um processo qualificado em sala de aula. Em 1926, a escola retornou para a Columbia, sendo, atualmente, chamada de Columbia University Library School (ROCKWOOD, 1968; DAVIS JR., 1976).

O século XX iniciou com novas escolas de Biblioteconomia sendo criadas e a ALA mostrando-se relutante em liderar o processo de ensino da Biblioteconomia. Bibliotecários de vários setores expressavam a sua preocupação com relação à ênfase excessiva no treinamento técnico, não oportunizando a discussão dos aspectos teóricos da área. Nessa época, Dewey desfrutava de prestígio junto à direção da ALA, como membro fundador, porém parte da direção da referida Associação era contrária à metodologia utilizada por ele. Alguns membros mostravam-se preocupados com o fato de que ex-alunos da Escola de Albany estavam criando novas instituições responsáveis pela formação de bibliotecários, adotando o mesmo modelo, porém sem possuir estrutura física e administrativa satisfatória. Como resultado da abdicação, por parte da ALA, em assumir o controle sobre o processo de formação nas escolas norte-americanas, houve oportunidade para a criação, em 1915, da Association of American Library Schools (AALS), entidade sem vínculo com a grande associação (DAVIS JR., 1976).

Em meio a inúmeras críticas a respeito da qualidade dos cursos responsáveis pela formação de bibliotecários, a Corporação Carnegie ${ }^{25}$, responsável pelo financiamento da maioria desses cursos, autorizou, em 1918, a investigação do ensino de Biblioteconomia pelo professor Charles Williamson ${ }^{26}$. Os resultados de suas descobertas foram publicados

\footnotetext{
${ }^{25}$ Carnegie Corporation of New York é a fundação filantrópica criada por Andrew Carnegie, em 1911, para promover o avanço da educação e a difusão do conhecimento. (https://www.carnegie.org/about/)

${ }^{26}$ Charles Clarence Williamson (1877-1965) Bibliotecário e diretor das Bibliotecas da Universidade de Columbia, professor da Columbia School of Library Service. Desempenhando funções nas Carnegie Foundation e Rockefeller Foundation.
} 
na Library Journal. Houve inúmeras críticas às escolas de Biblioteconomia, concluindo com uma advertência sobre a necessidade da elaboração de um plano visando assegurar que as demandas educacionais pudessem ser atendidas, pois, caso contrário, o futuro da profissão estaria fadado ao insucesso (DAVIS JR., 1976).

Com o número crescente de reclamações a respeito da qualidade de algumas escolas de Biblioteconomia, além dos efeitos do relatório do professor Williamson, a ALA criou, em 1924, o Conselho de Educação para Biblioteconomia (Board of Education for Librarianship - BEL) com a assistência da Carnegie Corporation, objetivando formular padrões provisórios, além de um plano para credenciar as escolas. Em 1925, em conferência da ALA, foram apresentadas as recomendações, entre as quais se destacam: a) tempo mínimo de 3 anos para a obtenção do título de bacharel em Biblioteconomia; b) criação de um exame de admissão padronizado; c) investimentos na qualificação do corpo docente; d) associação às universidades, deixando de atuar sem vinculação universitária; e) criação de cursos especiais específicos para capacitar bibliotecários para pequenas bibliotecas com orçamentos limitados, entre outras recomendações (STROHM et al., 1925).

A Biblioteconomia norte-americana carecia de uma escola voltada para a pesquisa em sua área, lacuna apontada pelo Conselho de Educação para Biblioteconomia (BEL). Em razão disso, a Fundação Carnegie, em 1928, através de um grande aporte financeiro, promoveu a criação da Graduate Library School, em Chicago, estabelecendo um novo padrão na formação dos bibliotecários naquele país. Tal iniciativa representou o ato de maior importância para o ensino de Biblioteconomia norte-americana, considerada, por muitos pesquisadores, como superior ao da criação da escola de Columbia (DAVIS JR, 1976; RICHARDSON JR., 2010; WINGER, 1961).

O programa de pesquisa estabelecido na Graduate Library School de Chicago passou a servir de inspiração e parâmetro a outras escolas de Biblioteconomia norte-americanas, bem como pela ALA. As pesquisas da área começaram a relacionar-se com outras áreas, tais como os estudos de comunicação de massa, a história intelectual e institucional, estrutura social contemporânea, estatística e epistemologia, resultando em um sensível crescimento de publicações periódicas da área, conferências, além de impulsionar a expansão do ensino na Pós-Graduação (WINGER 1961). 


\section{ENSINO DA BIBLIOTECONOMIA NO BRASIL}

No Brasil, o ensino de Biblioteconomia vai se desenvolver da fusão de diferentes influências do exterior. Porém, com maior destaque, ao longo da história, da escola norte-americana. Entretanto, as bibliotecas têm histórico anterior à formação de bibliotecários. As primeiras bibliotecas brasileiras estavam organizadas nos colégios jesuítas, em meados do século XVI. Na Bahia, a primeira biblioteca monástica é criada em 1582, em um mosteiro beneditino. Diversas ordens religiosas (franciscanos, carmelitas, mercedários etc.), que foram se estabelecendo, instalavam suas bibliotecas em acordo com a tradição - claustrum sine armario, quase castrum sine armamentario ${ }^{27}$ (FONSECA, 2007).

No século XIX, surgem bibliotecas pelo Brasil, em especial, bibliotecas públicas, que alcançam significativo esplendor, mas a maior parte entra em decadência, supostamente vítimas da burocracia pública. Poucas sobreviveram até os dias atuais renovadas e atualizadas. Destaque do período é a inauguração da Biblioteca Pública da Bahia, em 1811, sob a concepção de um plano elaborado e inspirado nos modelos de bibliotecas públicas de subscrição surgidas durante o século XVIII nos Estados Unidos e na Europa. Escrito por Pedro Gomes Ferrão Castelo Branco e impresso pela Typographia de Manuel Antônio da Silva Serva, "o Plano para estabelecimento de huma biblioteca pública na cidade de S. Salvador Bahia de Todos os Santos” (FONSECA, 2007, p.57). O documento, um folheto de quatro páginas, destacava que "o bibliotecário devera ser um sujeito de muito boa conduta, que saiba bem ler, escrever e contar, sendo muito para desejar-se que tenha conhecimento das línguas, principalmente a latina, francesa e inglesa". Um conjunto de qualificações esperada à época; bem como do tipo de serviço a ser prestado ao público (LEMOS, 2015, p.14).

Um século depois, em 1911, Manuel Cícero Peregrino da Silva, diretor da Biblioteca Nacional, estabeleceu, na Instituição, um curso de biblioteconomia, no qual a formação de bibliotecário estava baseada no estudo de bibliografia, paleografia e diplomática, iconografia e numismática, em uma indicação das novas necessidades da biblioteca, em relação ao apontado, anteriormente, por Castelo Branco. O Decreto $n^{\circ} 8.835$ de 11/07/1911 determinava, a exemplo das grandes bibliotecas internacionais, os objetivos decorrente do curso, de promover:

${ }^{27}$ Claustro sem livros é como quartel sem armamento (tradução do autor), (FONSECA, 2007, p.57). 
a) permutas internacionais; b) organização, segundo sistema de classificação decimal e por meio de fichas, do repertório bibliográfico brasileiro; c) impressão destas fichas para serem postas a venda; d) organização do catálogo coletivo das bibliotecas brasileiras; e) uso público dos repertórios e do catálogo coletivo. (LEMOS, 2007; RUSSO, 1966, p.15).

Outra manifestação importante ocorre na cidade de São Paulo, onde se instala um curso elementar de Biblioteconomia, em 1929, no Mackenzie College, atual Universidade; que foi ministrado pela bibliotecária norte-americana Dorothy Muriel Gedds Gropp. Em 23 de janeiro de 1930, a imprensa paulista destaca um curso também elementar de Biblioteconomia patrocinado pelo Instituto Histórico e Geográfico de São Paulo, o que indica o clima favorável para um curso regular, e que viria a ser instalado no Departamento de Cultura da Prefeitura do Município de São Paulo, coordenado e ministrado por Rubens Borba Alves de Moraes e Adelpha Silva R. Figueiredo. Em 1939, a subvenção dada ao curso pela Prefeitura é suprimida, o que obriga a transferência para o acolhimento da Escola de Sociologia e Política de São Paulo, instalando o curso em 1940. Contou também para a sobrevivência do curso uma subvenção financeira da Rockefeller Foundation, que permitiu ampliar o programa e oferecer bolsas de estudos. O êxito do curso que, a exemplo do curso de Biblioteconomia da Biblioteca Nacional, iria irradiar, nas décadas seguintes, a instalação de vários cursos de biblioteconomia pelo país (RUSSO, 1966).

Certamente, a história do curso de Biblioteconomia, no Brasil, é longa e permeada de fatos que não podem ser totalmente descritos neste texto. Indica-se, porém, que sua história se dissemina sob muito idealismo e entusiasmo, além do esforço pessoal de bibliotecários e de muitos outros, que, antes de se tornarem bibliotecários formais, já estavam envolvidos com a área.

\section{CONSIDERAÇÕES FINAIS}

Atualmente, no Brasil, o ensino da Biblioteconomia é resultado da fusão de diferentes influências estrangeiras, o que não deixa de representar a própria formação do brasileiro (OCHOLLA et al., 2015). Por esse motivo, faz-se importante conhecer, com uma maior riqueza de detalhes e de informações, as escolas que exerceram um forte impacto no perfil dos profissionais de Biblioteconomia formados no país.

Ao se adentrar na história da escola norte-americana de Biblioteconomia e da escola francesa École des Chartes, constatam-se fatos até então desconhecidos: a origem 
da Biblioteconomia Moderna na Alemanha e a relevância deste país junto aos profissionais da área nos Estados Unidos no século XIX; evidências de que a escola de Biblioteconomia criada por Melvin Dewey não atendia aos anseios da direção da ALA, a qual almejava a formação de um profissional bibliotecário mais erudito, seguindo o modelo europeu, ao contrário do proposto ao profissional egresso da Columbia College, com um perfil mais prático, para atender a situações do cotidiano de uma biblioteca; a provável influência exercida pelo modelo europeu no perfil profissional almejado no curso da Biblioteca Nacional, não ficando restrito à École des Chartes.

Diferentemente do que aconteceu nos primórdios do ensino de Biblioteconomia no Brasil, nos dias atuais, a importância não está mais restrita à escola norte-americana ou à escola francesa. Entre as décadas de 1970, 1980 e 1990, através de programas governamentais, muitos professores foram realizar cursos de mestrado e doutorado no exterior. Os países que mais receberam os professores/pesquisadores brasileiros foram França, Canadá, Espanha, Inglaterra e Estados Unidos. A volta dos professores representou a construção de um novo perfil científico nas escolas de Biblioteconomia e Ciência da Informação, mesclado com tendências teóricas estrangeiras, sem a existência de um perfil que relacione a essa ou àquela escola.

A harmonização entre uma formação mais técnica e a outra mais humanista possibilitará elevar o grau de reflexão e a consciência social e cultural do profissional bibliotecário, em consonância com o que se deseja para o/a futuro/a bibliotecário/a.

\section{REFERÊNCIAS}

ALMEIDA, N. B. F. de. Biblioteconomia no Brasil: análise dos fatos históricos da criação e do desenvolvimento do ensino. 2012. 159 f., il. Dissertação (Mestrado em Ciência da Informação) Universidade de Brasília, Brasília, 2012. Disponível em:

http://repositorio.unb.br/handle/10482/11170. Acesso em: 10 fev. 2018.

BETTANT, A. Histoire de la formation du bibliothécaire : du DTB à l'ENSB (1932-1963). Mémoire d'étude, p.9-33, 2012.

CHARON, A.; DIU, I.; PARINET, E. L'histoire des bibliothèques à l'École nationale des chartes: une tradition d'avenir. Bulletin des bibliothèques de France (BBF), 2005, n.2, p.23-28.

Disponível online: <http://bbf.enssib.fr/consulter/bbf-2005-02-0023-004>. ISSN 1292-8399.

CHARTIER, R. As origens culturais da Revolução Francesa. São Paulo: Editora da Unesp, 2009. COSTA, S. Revolução e Contra-Revolução na França. Goiânia: Garibaldi, 1999.

DAVIS JR., D. G. Education for Librarianship. Library Trends, v.25, n.1, p.113-134, Summer 1976. Disponível em: https://core.ac.uk/download/pdf/4816241.pdf. Acesso em: 23 mar. 2019. DELPIT, M. M. Notice historique sur l'Ecole des chartes. Bibliothèque de l'Ecole des Chartes, v.l, t.1, p.1-42, 1840. 
DEMANTE, A.-G. L'École des chartes en 1840. Bibliothèque de l'école des chartes, Paris, t.59, p.812-814, 1898. Disponível em: https://www.persee.fr/doc/bec_0373-

6237_1898_num_59_1_462956. Acesso em: 14 jun 2019.

DIAS, A. C. O ensino de biblioteconomia no Brasil. 2. ed. Rio de Janeiro, IPASE, 1955.

ÉCOLE NATIONALE DES CHARTES (França). Une institution au service de l'histoire et du patrimoine depuis 1821. 2016. Disponível em: http://www.chartes.psl.eu/fr/rubriqueecole/institution-au-service-histoire-du-patrimoine-1821. Acesso em: 17 jul. 2019.

FONSECA, E. N. da. Introdução à Biblioteconomia. 2. ed. Brasília: Briquet de Lemos/Livro, 2007. FORTESCUE, W. Revolução e contra-revolução na França, 1815-1852. São Paulo: Martins Fontes, 1992.

FRÉDÉRICQ, P. L'enseignement supérieur de l'histoire à Paris, notes et impressions de Voyage. Revue internationale de l'enseignement, p.746-752, $2^{\mathrm{e}}$ semestre 1883.

GROGAN, D. J. Education for librarianship: some persistent issues. Education for Information, v.25, n.1, p.5-26, 2007. Disponível em: <http://search-ebscohost-

com.ez67.periodicos.capes.gov.br/login.aspx?direct=true\&db=iih\&AN=25551402\&lang=ptbr\&site=ehost-live $>$. Acesso em: 13 jul. 2019.

HESSEL, A. A History of Libraries (Translated, with supplementary material by Reuben Peiss). Scarecrow Press: New Brunswick, New Jersey, 1955.

HJØRLAND, B. Library and Information Science (LIS), Part 1. Knowledge Organization, v.45, n.3, p.232-254, 2018. Disponível em: <http://search-ebscohost-

com.ez67. periodicos.capes.gov.br/login.aspx?direct=true\&db=iih\&AN=131123119\&lang=ptbr\&site=ehost-live >. Acesso em: 13 jul. 2019.

HOTTIN, C. L'Ecole des chartes: Architecture et institutionnalité. Universités et grandes écoles à Paris, Paris, p.100-105, 1999. Disponível em: https://halshs.archives-ouvertes.fr/halshs00089095/document. Acesso em: 08 jun. 2019.

LEMOS, A. A. B. de. Vacilações e tendências do ensino da biblioteconomia. In: LEMOS, A. A. B. de. De bibliotecas e biblioteconomias: percursos. Brasília: Briquet de Lemos/Livros, 2015. MARTIN, H.-J. Les Chartistes et les bibliothèques. Bulletin des bibliothèques de France (BBF), n.12, p.529-537, 1972. Disponível em: <http://bbf.enssib.fr/consulter/bbf-1972-12-0529-001>. Acesso em: 12 mar. 2018.

MEY, E. S. A.; SILVEIRA, N. C. Catalogação no plural. Brasília: Briquet de Lemos, 2009. MORAES, L. E. História contemporânea: da Revolução Francesa à Primeira Guerra Mundial. São Paulo: Contexto, 2017.

MUELLER, S. P. M. O ensino de biblioteconomia no Brasil. Ciência da Informação, v.14, n.1, p.3-15, 1985. Disponível em: <http://basessibi.c3sl.ufpr.br/brapci/v/a/5576>. Acesso em: 16 Mar. 2017.

OCHOLLA, D. N. et al. A Comparison of Cataloguing and Classification Education (CCE) in Library and Information Science in South Africa, Brazil and the USA (SOBUSA): An Overview. African Journal of Library, Archives \& Information Science, v.25, n.1, p.15-27, 2015. Disponível em: $<$ http://search.ebscohost.com/login.aspx?direct=true\&db=aph\&AN=102893879\&lang=ptbr\&site=eds-live >. Acesso em: 19 jul. 2019.

PALLIER, D. Histoire et évolution du métier de bibliothécaire. Bulletin d'informations de l'ABF, $\mathrm{n}^{\circ}$ 164, p.47-56, 1994.

PRADO, H. de A. Entrevista. Revista Brasileira de Biblioteconomia e Documentação, São Paulo, v.21, n.3/4, p.1-6, jul./dez. 1988.

QUINN, M. E. Historical Dictionary of Librarianship. Lanham (USA): Rowman \& Littlefiel, 2014. RAYWARD, W. B. Melvil Dewey and Education for Librarianship. The Journal of Library History, v.3, n.4, p.297-312, 1968. Disponível em: https://www.jstor.org/stable/25540125. Acesso em: 11 jun. 2019. 
RICHARDSON JR., J. V. History of American Library Science: Its Origins and Early Development. Encyclopedia of library and information sciences. 3rd ed. New York, NY: Taylor and Francis, 2010. Disponível em: https//:polaris.gseis.ucla.edu/jrichardson?ALS.pdf. Acesso em: 12 jun. 2019. ROCKWOOD, R. H. Melvil Dewey and Librarianship. The Journal of Library History, v.3, n.4 p.329-341, 1968. Disponível em: http://www.jstor.org/stable/25540127. Acesso em: 11 jun. 2019.

RUSSO, L. G. M. A biblioteconomia brasileira: 1915-1965. Rio de Janeiro: Instituto Nacional de Livro, 1966.

SOUZA, F. das C. de. O ensino de Biblioteconomia no contexto brasileiro. Florianópolis: UFSC, 2009.

STROHM, A., et al. FIRST ANNUAL REPORT OF THE BOARD OF EDUCATION FOR LIBRARIANSHIP. Bulletin of the American Library Association, v.19, n.4, p.226-263, 1925.

Disponível em: www.jstor.org/stable/25686411. Acesso em: 13 abr. 2019.

WEITZEL. S. da R. Desenvolvimento de coleções no curso de Biblioteconomia da Biblioteca Nacional (1915-1949). Anais da Biblioteca Nacional, Rio de Janeiro, v.130, p.111-220, 2010. Disponível em: http://memoria.bn.br/pdf/402630/per402630_2010_00130.pdf. Acesso em: 24 abr. 2019.

WINGER, H. W. Aspects of Librarianship: A Trace Work of History. The Library Quarterly: Information, Community, Policy, v.31, $n^{\circ}$. 4, p.321-35, 1961. Disponível em:

http://www.jstor.org/stable/4305157. Acesso em: 26 fev. 2019. 